\section{Childhood psychopathology at age 8 predicts antidepressant use by age 24}

\section{QUESTION}

Question: Does childhood psychopathology predict lifetime use of antidepressants?

Population: 5547 individuals from a nationwide Finnish birth cohort born in 1981. Of the entire birth cohort ( $n=60007$ ), 6017 children were selected to participate in 1989 at age 8 . Individuals whose data could not be linked to the prescription database were excluded.

Setting: General population, Finland; 1981-2005.

Prognostic factors: The main prognostic factor assessed was childhood psychopathology (assessed at age 8 by validated parent and teacher Rutter's Questionnaire composed of a conduct scale, a hyperkinetic scale and an emotional scale, and the validated self-reported Children's Depression Inventory). Individuals were described as having problems if they scored above the 90th percentile on any of the psychopathology scores. Other factors assessed were parental education level and family structure (defined as intact if living with two biological parents and non-intact if otherwise).

Outcomes: Reimbursed antidepressant purchase between age 13 and 24 (ie, between 1994 and 2005), identified from the Nationwide Prescription Register.

\section{METHODS}

Design: Cohort study.

Follow-up period: 16 years.

\section{MAIN RESULTS}

For the entire sample, $8.9 \%$ of males and $13.8 \%$ of females made at least one antidepressant purchase between the ages of 13 and 24. For males as well as females, antidepressant use between age 13 and 24 was predicted by living in a non-intact family structure at age 8 (male HR 1.4, 95\% CI 1.002 to 1.9 , $\mathrm{p}=0.049$; female HR $1.5,95 \%$ CI 1.1 to $1.9, \mathrm{p}=0.004$ ), having emotional problems (male HR 1.4, 95\% CI 1.01 to 2.0, $p=0.04$; female HR $1.5,95 \%$ CI 1.1 to $2.0, p=0.01$ ) or having problems with depressive symptoms (male HR 1.8, 95\% CI 1.3 to 2.5, $\mathrm{p}<0.001$; female HR 1.6, $95 \%$ CI 1.2 to $2.2, \mathrm{p}=0.001$ ). For males only, antidepressant use between age 13 and 24 was additionally predicted by having conduct problems (HR 1.9, $95 \%$ CI 1.4 to $2.7, \mathrm{p}<0.001)$. Hyperkinetic symptoms at age 8 did not predict later antidepressant use in males or females in multivariate analyses. Highest risk for antidepressant use among males was associated with conduct, with $17.5 \%$ of males with conduct problems at age 8 later purchasing antidepressants, as compared with $8.4 \%$ of males without conduct problems at age 8 . The highest risk among females was associated with self-reported depressive scale scores, with $20.4 \%$ of females with problems with depressive symptoms at age 8 later purchasing antidepressants, as compared with $13.0 \%$ of those without such problems.

\section{CONCLUSIONS}

Several measures of child psychopathology at age 8, including emotional, conduct and depressive problems, predict purchase of antidepressants later in childhood/early adulthood. The types of psychopathology that predict later antidepressant use vary between males and females. Living in families that did not include both biological parents at age 8 also predicted antidepressant purchases later in life.

\section{ABSTRACTED FROM \\ Gyllenberg D, Sourander A, Niemelä S, et al. Childhood predictors of use and costs of antidepressant medication by age 24 years: findings from the Finnish nationwide 1981 Birth} Cohort Study. J Am Acad Child Adolesc Psychiatry 2011;50:406-15, 415.e1.

Correspondence to Dr David Gyllenberg, Department of Child Psychiatry, University of Helsinki, P0 Box 22, 00014 Helsinki, Finland; david.gyllenberg@helsinki.fi

Sources of funding National Social Insurance Institution of Finland, the Medical Society of Finland and the Child Psychiatric Research Foundation.
F ew prospective epidemiological studies are able to examine childhood predictors of antidepressant use in adolescence and early adulthood, principally because of a lack of reliable data about antidepressant use. The study by Gyllenberg and colleagues links data about childhood psychiatric problems measured at 8 years of age from the Finnish 1981 Birth cohort study with national register based lifetime information about purchases of antidepressants between 13 and 24 years of age. They report that childhood emotional symptoms and depressive symptoms independently predicted later antidepressant use for males and females, whereas conduct symptoms only predicted antidepressant use for males.

This study provides further evidence for the importance of early identification of childhood psychopathology, as well suggesting the need for targeting primary prevention and intervention efforts in early childhood. Antidepressant use in adolescence is likely a good proxy for more serious psychopathology, as are psychiatric symptoms at age of 8 . However, juvenileonset disorders may have a different risk profile than adult-onset disorder, and predictors of antidepressant use may also differ.

The results of this study support those of others that have demonstrated continuities between childhood internalising problems, such as emotional and depressive symptoms, and adulthood internalising problems, ${ }^{1}$ as well as studies that have demonstrated discontinuities between childhood externalising problems, such as conduct problems, and adulthood internalising problems. ${ }^{2}$ Future studies need to replicate these results and examine why childhood conduct problems may not predict antidepressant use for females.

Overall, the associations between childhood psychopathology and antidepressant use were moderate - other psychosocial factors that have not been adjusted for could account for the observations. Gaps in knowledge exist about which other factors in childhood are associated with antidepressant use and may moderate antidepressant use. Data from birth cohorts should be further examined to enrich the picture.

\section{Charlotte Clark}

Centre for Psychiatry, Barts and the London School of Medicine, Queen Mary University of London, London, UK

Competing interests None.

\section{REFERENCES}

1. Rutter M, Kim-Cohen J, Maughan B. Continuities and discontinuities in psychopathology between childhood and adult life. J Child Psychol Psychiatry 2006;47:276-95.

2. Kim-Cohen J, Caspi A, Moffitt TE, et al. Prior juvenile diagnoses in adults with mental disorder: developmental follow-back of a prospectivelongitudinal cohort. Arch Gen Psychiatry 2003;60:709-17. 